\title{
Pigment transfer from phytoplankton to zooplankton with emphasis on astaxanthin production in the Baltic Sea food web
}

\author{
M. Andersson, L. Van Nieuwerburgh, P. Snoeijs* \\ Department of Plant Ecology, Evolutionary Biology Centre, Uppsala University, Villavägen 14, 75236 Uppsala, Sweden
}

\begin{abstract}
The carotenoid astaxanthin is a powerful antioxidant and a compound of vital importance for many marine organisms such as crustaceans and salmonids. Although astaxanthin deficiency may have serious consequences for ecosystem functioning, its origin and transfer in the food web have been little studied. Astaxanthin is produced by planktonic crustaceans, but these cannot synthesise carotenoid pigments de novo; they rely on the availability of astaxanthin precursors through the consumption of phytoplankton algae. We performed 4 laboratory experiments to test how the production of astaxanthin in wild pelagic copepod communities (mainly consisting of Acartia) is affected when different phytoplankton communities (unfertilised, fertilised with N and P, or fertilised with $\mathrm{N}, \mathrm{P}$ and $\mathrm{Si}$ ) are supplied as prey. We show that phytoplankton community composition and biomass have profound effects on the production of astaxanthin in calanoid copepods. When they were grazing on a diverse phytoplankton community with high biomass dominated by chlorophytes, dinoflagellates and diatoms with thin silica frustules, astaxanthin production in the copepods was highest. It was lower when the copepods were fed with low phytoplankton biomass or high biomass dominated by large heavily silicified diatoms; these diatoms were not consumed and grazing was mainly on prymnesiophytes. When the astaxanthin production was high, maximum astaxanthin content per copepod individual of about twice the initial level was reached during sunrise. These results suggest increased feeding activity and astaxanthin production during the night and utilisation of astaxanthin for photoprotection and other antioxidant activities during the day.
\end{abstract}

KEY WORDS: Astaxanthin · Carotenoids · Food web · Phytoplankton · Zooplankton · Copepods · Grazing $\cdot$ Baltic Sea

Resale or republication not permitted without written consent of the publisher

\section{INTRODUCTION}

Large-scale environmental changes have occurred in the brackish Baltic Sea during the last $50 \mathrm{yr}$, and some of these changes have been caused by eutrophication (Elmgren 1989, Jansson \& Dahlberg 1999). Shifts in phytoplankton community composition are a universal consequence of increased availability of nitrogen and/or phosphorus (Snoeijs 1999). This, in turn, may affect the whole food web since the primary producers provide vital nutrients for higher trophic levels. For example, the M74 syndrome, a reproductional disturbance in the Baltic populations of the Atlantic salmon Salmo salar L., is generally considered to be related to large-scale environmental changes (Lundström et al. 1998, Bengtsson et al. 1999). This serious threat to wild Baltic salmon stocks has been shown to be associated with low thiamine and astaxanthin levels in fish fry (Amcoff et. al 1998, Pettersson \& Lignell 1999) and alterations in fatty acid composition in eggs (Pickova et al. 1999).

Studies from the Black and Baltic Seas have shown that eutrophication increases primary production, and diatoms are replaced by other phytoplankton groups such as dinoflagellates and prymnesiophytes (Leppäkoski \& Mihnea 1996). However, when silicate is not limiting, diatoms are usually the best competitors. This has been shown in numerous laboratory and mesocosm 
experiments (e.g. Sommer 1994, Jacobsen et al. 1995). Although it is well known that copepods do not feed exclusively on diatoms (Paffenhöfer 2002), diatoms are generally thought to serve as a high-quality food source for higher trophic levels, such as copepods (Runge 1988, Legendre 1990, Koski et al. 1998). However, recently this function of diatoms in the food web has also been questioned and is a matter of debate, as it challenges the classical view of marine food web energy flow from diatoms to fish by means of copepods (Kleppel 1993, Jónasdóttir et al. 1998). Based on both laboratory and in situ studies, it has been proposed that many diatom species, especially at bloom concentrations, are able to inhibit the production and viability of pelagic copepods' eggs (Ban et al. 1997, Miralto et al. 1999, Paffenhöfer 2002). However, in a recent large data compilation, no negative relationships could be detected between copepod egg hatching success and either diatom biomass or dominance in the microplankton in any of 12 globally distributed areas where diatoms dominate the phytoplankton community (Irigoien et al. 2002). Further phytoplankton characteristics that have been shown to affect the rates of development, somatic growth and reproduction of copepods include cell size, cell morphology, toxicity, mineral composition and content of some biochemical components, such as amino acids, polyunsaturated fatty acids, sugars and vitamins (Koski et al. 1998 and references therein). However, little is known about the transfer of carotenoids from phytoplankton to pelagic copepods.

In the present study we investigate whether the production of the important antioxidant astaxanthin (Edge et al. 1997) in copepods depends on their microalgal diet. Pigments can be used to trace the algal diet of zooplankton because pigment composition typically varies between phytoplankton groups, e.g. alloxanthin is typical of cryptophytes, peridinin of dinoflagellates, prasinoxanthin of prasinophytes, 19'-hexanoyloxy-fucoxanthin of prymnesiophytes, chlorophyll $b$ (chl b) of chlorophytes, prasinophytes and euglenophytes, fucoxanthin of diatoms, prymnesiophytes, chrysophytes and raphidophytes, etc. (Jeffrey \& Vesk 1997). $\beta$-carotene obtained from phytoplankton is considered to be the main precursor for astaxanthin synthesis in zooplankton via other carotenoids such as zeaxanthin and lutein (Katayama et al. 1973, Kleppel et al. 1985). Although $\beta$-carotene basically occurs in all microalgae, quantitative differences occur between phytoplankton groups, while zeaxanthin and lutein only occur in some groups, notably cyanobacteria and chlorophytes (Jeffrey \& Vesk 1997). We performed 4 laboratory experiments to test if and how the production of astaxanthin in wild copepod communities (mainly consisting of Acartia) is affected when different phytoplankton communities (unfertilised, fertilised with $\mathrm{N}$ and $\mathrm{P}$, or fertilised with $\mathrm{N}, \mathrm{P}$ and $\mathrm{Si}$ ) are supplied as food.

\section{MATERIALS AND METHODS}

The experiments were carried out at the Zingst field station, Germany, in the southern Baltic Sea proper $\left(54^{\circ} 25^{\prime} \mathrm{N}, 12^{\circ} 40^{\prime} \mathrm{E}\right)$. Phytoplankton communities were obtained from 1600 l mesocosms where different phytoplankton blooms were created by manipulations of natural seawater (NSW) of $8.5 \mathrm{psu}$ with nutrients (Table 1). For further description of the mesocosms, see Barros et al. (2003). In the morning of each sampling day, 251 of water were sampled (after careful mixing of the water in the mesocosms) from each of 3 replicate mesocosms, and filtered through a $100 \mu \mathrm{m}$ mesh plankton net. Thus, the final phytoplankton stock consisted of 751 seawater with organisms $<100 \mu \mathrm{m}$ in a large plastic container, which was stored in the laboratory until the start of the experiment on the afternoon of the same day. For the NSW treatment, the water was sampled directly from the sea, where the copepod stock was also collected.

For each experiment, new calanoid copepods were collected with a $200 \mu \mathrm{m}$ mesh size plankton net at 0 to

Table 1. Summary of the 4 different treatments of the phytoplankton communities prior to the grazing experiments. The NSW treatment consisted of natural seawater sampled directly from the Baltic Sea. For the other 3 treatments phytoplankton blooms were created in $1600 \mathrm{l}$ mesocosms by nutrient additions. Each day, the mesocosms also received trace metals, chelators and vitamins in $0.5 \%$ of f/2 medium concentrations (Guillard \& Ryther 1962) but excluding thiamine

\begin{tabular}{|c|c|c|c|}
\hline Treatment & $\begin{array}{l}\text { Daily nutrient } \\
\text { additions to the } \\
\text { mesocosms }\end{array}$ & $\begin{array}{l}\text { Number of days } \\
\text { of mesocosm } \\
\text { cultivation }\end{array}$ & $\begin{array}{l}\text { Sampling } \\
\text { day }\end{array}$ \\
\hline NSW & None & 0 & 1 September 2002 \\
\hline NP & $\begin{array}{l}4 \mu \mathrm{M} \mathrm{NaNO} \\
0.25 \mu \mathrm{M} \mathrm{NaH}_{2} \mathrm{PO}_{4} \\
28 \mu \mathrm{M} \mathrm{NaHCO} 3\end{array}$ & 11 & 11 July 2001 \\
\hline NPSi1 & $\begin{array}{l}4 \mu \mathrm{M} \mathrm{NaNO}{ }_{3} \\
0.25 \mu \mathrm{M} \mathrm{NaH}_{2} \mathrm{PO}_{4} \\
12 \mu \mathrm{M} \mathrm{Na}_{2} \mathrm{SiO}_{3} \\
28 \mu \mathrm{M} \mathrm{NaHCO} \\
3 \mathrm{NaCO}_{3}\end{array}$ & 9 & 9 July 2001 \\
\hline NPSi2 & $\begin{array}{l}4 \mu \mathrm{M} \mathrm{NaNO}_{3} \\
0.25 \mu \mathrm{M} \mathrm{NaH}_{2} \mathrm{PO}_{4} \\
12 \mu \mathrm{M} \mathrm{Na}_{2} \mathrm{SiO}_{3} \\
28 \mu \mathrm{M} \mathrm{NaHCO}\end{array}$ & 11 & 12 September 2001 \\
\hline
\end{tabular}


$10 \mathrm{~m}$ depth, about $1.5 \mathrm{~km}$ offshore. Sampling took place in the morning of each experimental day and the copepods were stored in a $10 \mathrm{l}$ container in NSW for transport to the laboratory. Within $0.5 \mathrm{~h}$ of sampling the copepod sample was diluted to $\sim 50 \mathrm{l}$ with filtered NSW and cleansed of macroalgae and dead (floating) zooplankton. The final copepod stock was stored in the laboratory until the start of the experiment. Thus, the copepods were starved for $\sim 6 \mathrm{~h}$ prior to each experiment. A quick estimate of the copepod density in the stock was made by counting the number of individuals in triplicate $100 \mathrm{ml}$ well-mixed samples. For each experiment, 3 samples from the copepod stock were fixed with Lugol's solution for later identification and exact density determination.

All experiments were started between 16:00 and 17:00 h. Altogether, thirty-nine 21 polypropylene jars (height $18 \mathrm{~cm}$, diameter $14 \mathrm{~cm}$ ) were filled with $1.5 \mathrm{l}$ of phytoplankton stock, then placed on a table in the laboratory exposed to natural daylight (but not to direct sunlight to avoid aggregations of copepods and flagellates) through an open door. Room temperature was 20 to $25^{\circ} \mathrm{C}$. A fixed volume of the copepod stock (based on the fast estimates of copepod density) was poured through plexiglas insets (height $16 \mathrm{~cm}$, diameter $13 \mathrm{~cm}$ ) with $200 \mu \mathrm{m}$ mesh size plankton net bottoms to obtain an approximate density of 50 copepod individuals $1^{-1}$ (75 inset $\left.{ }^{-1}\right)$. One inset with copepods was placed in each jar. Thus, the phytoplankton $(<100 \mu \mathrm{m})$ that was already in the seawater in the jars and the copepods $(>200 \mu \mathrm{m})$ on the net of the inset were mixed. The triplicate zero sampling $(t=0 \mathrm{~h})$ took place before copepods were added to the other 36 jars. These jars were randomly sampled in triplicate after $t=1,2,3,4$, $5,7,9,12,15,18,21$ and $24 \mathrm{~h}$ of copepod grazing. The copepod samples (including the $t=0$ samples) consisted of all copepods from 1 jar, and were obtained by taking out the inset and rinsing the net with filtered seawater. Phytoplankton samples (110 to $150 \mathrm{ml}$ ) were taken from each jar after careful mixing. The copepod samples were filtered on Whatman ${ }^{\mathrm{TM}} \mathrm{GF} / \mathrm{C}$ filters, and the phytoplankton samples on Whatman ${ }^{\mathrm{TM}} \mathrm{GF} / \mathrm{F}$ filters. During filtering it was observed that all or the vast majority of the copepods were alive at this point, in all experiments. The filters were wrapped in aluminium foil, immediately frozen in liquid nitrogen and within 2 wk transported to Uppsala, where they were stored at $-86^{\circ} \mathrm{C}$ in a freezer until pigment analyses were carried out (within $4 \mathrm{mo}$ ).

Chlorophylls and carotenoids were extracted from the filters according to Wright et al. (1997). The phytoplankton filters were sonicated for $1 \mathrm{~min}$ in cold methanol on ice (Vibra Cell ${ }^{\mathrm{TM}}$, pulse $0.9 \mathrm{~s}$, amplitude 92) and centrifuged for $4 \mathrm{~min}$ at $4{ }^{\circ} \mathrm{C}$ and $6000 \times g$, after which the pigments were immediately analysed. The copepod filters were sonicated for $1 \mathrm{~min}$ in cold acetone on ice (Vibra Cell ${ }^{\mathrm{TM}}$, pulse $0.9 \mathrm{~s}$, amplitude 92), left overnight in the dark at $4^{\circ} \mathrm{C}$ (Buffan-Dubau \& Carman 2000), centrifuged for $4 \mathrm{~min}$ at $4^{\circ} \mathrm{C}$ and $6000 \times g$, after which the pigments were immediately analysed.

For pigment separation the reversed-phase HPLC method of Wright \& Jeffrey (1997) was used with a slightly modified solvent system program. A volume of 100 to $150 \mu \mathrm{l}$ was injected into the HPLC system using an autoinjector (Spark Holland ${ }^{\mathrm{TM}}$, Promis II). Two different reversed-phase $\mathrm{C}-18$ columns were used: a Spherisorb 5ODS, $250 \times 4.60 \mathrm{~mm}, 5 \mu \mathrm{m}$ particle size, Phenomenex ${ }^{\mathrm{TM}}$ for the phytoplankton samples and a Reprosil-Pur C18-Aq column, $250 \times 4$ mm, $5 \mu \mathrm{m}$ particle size, Dr. A. Maisch ${ }^{\mathrm{TM}}$ for the copepod samples. The first column separated algal pigments better (e.g. it gave an almost complete separation of lutein and zeaxanthin), while the second column detected astaxanthin. Pigments were detected at $436 \mathrm{~nm}$ with a variable wavelength UV detector (Milton Roy ${ }^{\mathrm{TM}}$ spectroMonitor 3100) coupled to a multiple solvent delivery system (Milton Roy ${ }^{\mathrm{TM}} \mathrm{CM}$ 4000). Pigment calibration was achieved using a 5 -point calibration curve (with dilutions made in triplicate $=15$ injections) with the following pigment standards: canthaxanthin and zeaxanthin from Roth ${ }^{\mathrm{TM}}$, astaxanthin, $\beta, \beta$-carotene, $\beta, \varepsilon$-carotene, chlorophyll $a$ $(\mathrm{chl} a)$, chl $b$, lutein and lycopene from Sigma ${ }^{\mathrm{TM}}$, alloxanthin, antheraxanthin, 19'-butanoyloxy-fucoxanthin, chlorophyll $C(\mathrm{chl} C)$, diadinoxanthin, diatoxanthin, echinenone, fucoxanthin, 19'-hexanoyloxy-fucoxanthin, peridinin, prasinoxanthin and violaxanthin from DHI Water \& Environment ${ }^{\mathrm{TM}}$, Denmark. Mono- and diester forms of astaxanthin were identified with the help of cultivated Haematococcus pluvialis cysts in which esterified forms of astaxanthin dominate the pigment composition, and they were quantified using the calibrated equation for free astaxanthin.

Microscopic observations established that less than $2 \%$ of the cells in our 4 phytoplankton stocks consisted of small zooplankton (some ciliates) and heterotrophic flagellates, and no larger zooplankton organisms occurred in these stocks. Therefore we assumed in our calculations that the pigments in the phytoplankton samples included negligible amounts of zooplankton pigments. We also observed that some of the calanoid copepods carried epizoic microalgae on their body surfaces, predominantly chlorophytes, but also some diatoms. This is a problem when quantifying the transfer of carotenoids from phytoplankton to copepods. Another problem was that, unavoidably, some microalgae from the phytoplankton stock became trapped on the $200 \mu \mathrm{m}$ net when sampling the copepods, and thus became a part of the copepod samples. The third problem was that the copepods still may have had some algal pigments in their guts, even after $\sim 6 \mathrm{~h}$ of starvation. To 
solve these problems, we designed a net transfer ratio $\left(\mathrm{TR}_{\text {net, }}\right.$ Fig. 1) to enable us to compare the transfer of carotenoids from the different phytoplankton communities to the copepods. The $\mathrm{TR}_{\text {net }}$ was defined as $\mathrm{TR}_{\text {net }}=$ $\mathrm{TR}_{\mathrm{t}=\mathrm{z}}-\mathrm{TR}_{\mathrm{t}=0}$, where $\mathrm{TR}=\left([\mu \mathrm{mol}]^{-1}\right.$ of carotenoid in the
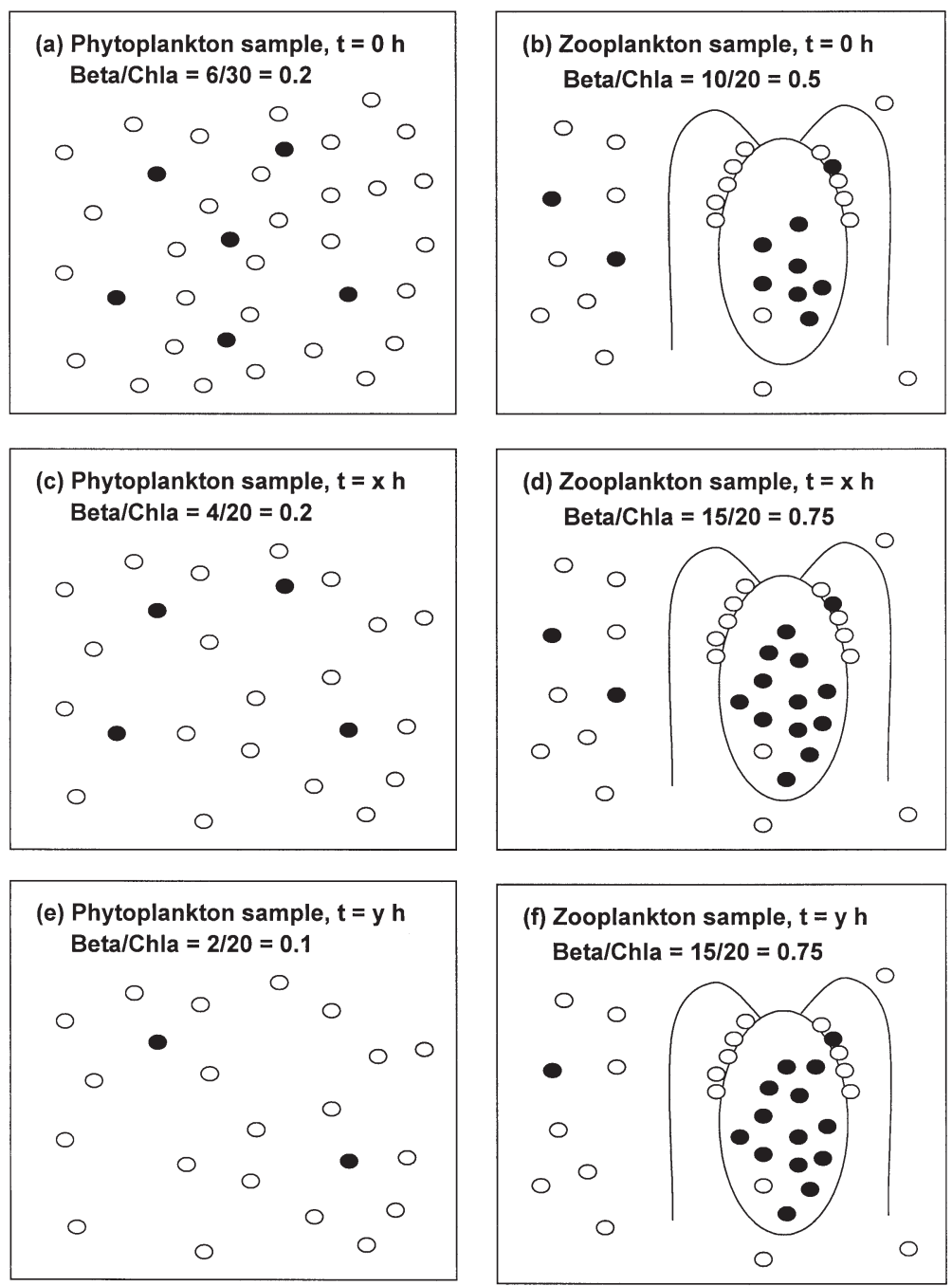

Fig. 1. Explanation of the transfer ratio $\left(\mathrm{TR}_{\mathrm{net}}\right)$ used for comparisons of the transfer of carotenoids from the different phytoplankton communities to the copepods, using different scenarios. Open circles represent 1 molecule of chlorophyll a ( $\mathrm{chl} \mathrm{a)} \mathrm{and} \mathrm{black} \mathrm{dots} \mathrm{represent} 1$ molecule of $\beta$-carotene (beta). (a) and (b) illustrate the $t=0$ sampling. Phytoplankton sample contains molecules of beta and chl $a$ in a certain ratio (here 0.2 ) and the copepod sample contains beta and chl $a$ in a certain ratio (here 0.5 ). In the copepod sample the ratio depends on the concentrations of these pigments in and on the copepod body and in the fraction of the phytoplankton sample trapped on the $200 \mu \mathrm{m}$ plankton net. (c) and (d) illustrate sampling after $\times \mathrm{h}$ of grazing where the ratio in the phytoplankton has stayed the same (no selective grazing), and the copepods have enriched beta in their bodies while chl a has been excreted or destroyed. In this case $\mathrm{TR}_{\text {net }}=\mathrm{TR}_{X}-\mathrm{TR}_{0}=(0.75 / 0.2)-(0.5 / 0.2)=1.25$. (e) and (f) illustrate sampling after $y \mathrm{~h}$ of grazing where the ratio in the phytoplankton has changed due to selective grazing on a specific algal group, and the copepods have enriched beta in their bodies while chl a has been excreted or destroyed. In this case $\mathrm{TR}_{\mathrm{net}}=\mathrm{TR}_{X}-\mathrm{TR}_{0}=(0.75 / 0.1)-(0.5 / 0.2)=5.0$ copepod sample]/[umol $\mathrm{l}^{-1}$ of chl $a$ in the copepod sample] $) /\left(\left[\mu \mathrm{mol} \mathrm{l}^{-1}\right.\right.$ of carotenoid in the phytoplankton ele]/[umol $\mathrm{l}^{-1}$ of chl $a$ in the phytoplankton sample]). For algal carotenoids used by the copepods to dy pigments (e.g. $\beta$-carotene, zeaxanthin, lutein), a positive $\mathrm{TR}_{\text {net }}$ expresses the degree of enrichment of a specific carotenoid by the copepods and a negative $\mathrm{TR}_{\text {net }}$ the degree of loss of this carotenoid from the copepods. For algal carotenoids not used by the copepods to synthesise body pigments (e.g. 19'hexanoyloxy-fucoxanthin, peridinin, fucoxanthin, diadinoxanthin), a positive $\mathrm{TR}_{\text {net }}$ expresses the degree of selective grazing by the copepods on certain groups of microalgae and a negative $\mathrm{TR}_{\text {net }}$ expresses selection against certain groups of microalgae.

To summarise the variation in pigment composition among the samples, principal component analysis (PCA), implemented with the programme CANOCO (ter Braak \& Šmilauer 1998), was applied to relative abundances of the pigments on a molar basis. To describe similarity in pigment composition between 2 samples, the Sørensen similarity index for quantitative samples was calculated, based on the same relative abundances: $\mathrm{S}=(2$ $\left.\mathrm{M} /\left[\mathrm{M}_{1}+\mathrm{M}_{2}\right]\right) \times 100 \%$, where $\mathrm{M}$ is the sum of the smaller values of the species common to both samples, $M_{1}$ is the sum of all values in the first sample and $\mathrm{M}_{2}$ is the sum of all values in the second sample. (Mueller-Dombois \& Ellenberg 1974). In our case, this measure of similarity varies from $0 \%$ for 2 samples with no carotenoids in common to $100 \%$ for 2 samples with identical carotenoid composition. Linear regression analyses were carried out with the programme MINITAB ${ }^{\text {TM }}$ Version 13.1.

\section{RESULTS}

Altogether, 25 pigments were identified in the phytoplankton samples and 25 in the copepod samples. Of these pigments, 11 occurred in both sample types (with zeaxanthin/lutein considered as 1). The sample scores of the PCA analysis showed that the phytoplankton pigment compositions of the 2 NPSi treatments 
were similar (Fig. 2a). Also the phytoplankton pigment compositions of the NSW and NP treatments were similar to each other, but quite unlike those of the NPSi treatments (Fig. 2a). The 2 sample pairs NSW/NP and
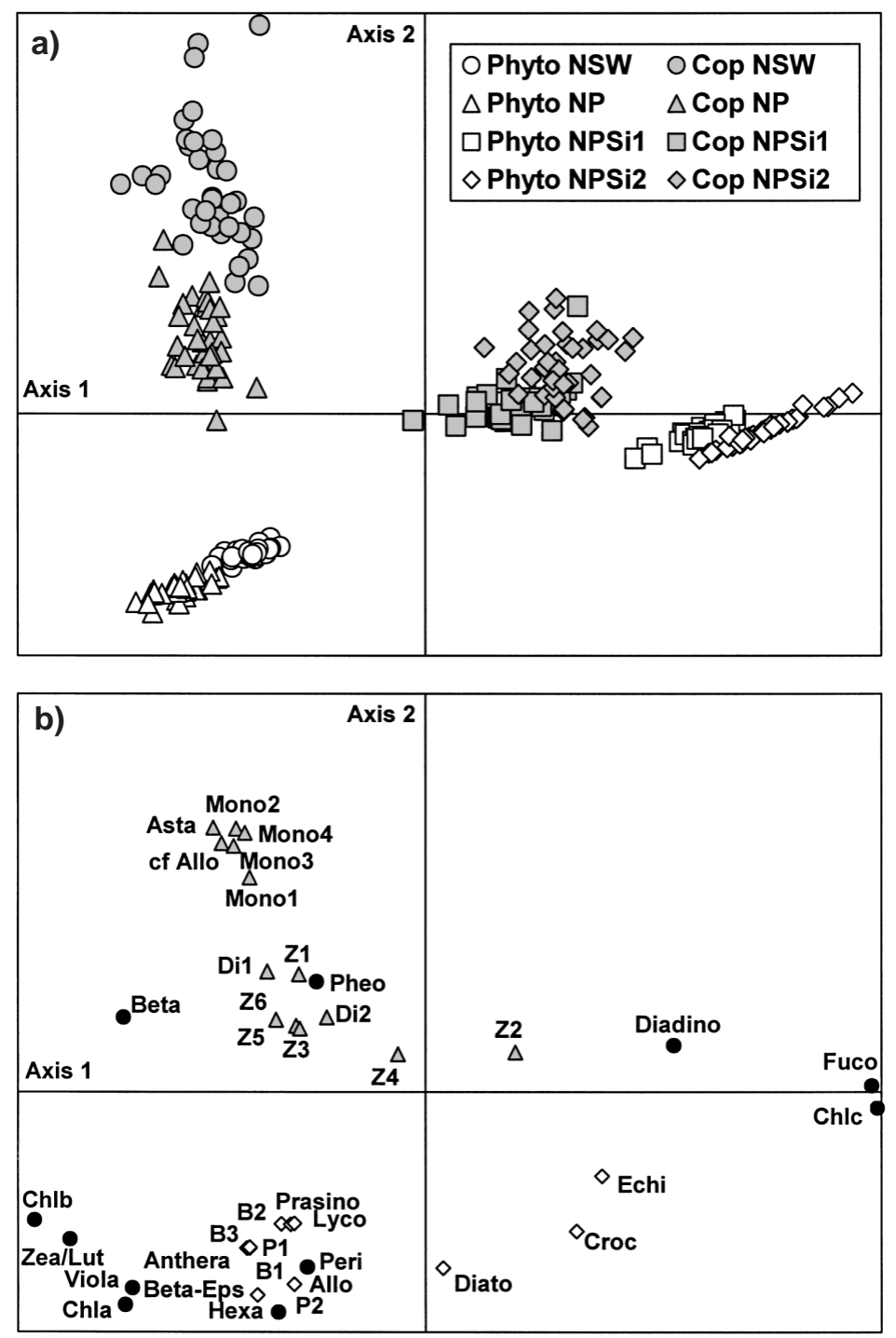

Fig. 2. Ordination plot of the PCA analysis of the pigment composition of all samples, showing Axes 1 and 2 (eigenvalues 0.70 and 0.24 , respectively). (a) Sample scores for phytoplankton samples (Phyto) and copepod samples (Cop). (b) Pigment scores, $\diamond=13$ pigments unique to the phytoplankton samples (some scores overlapping), $\Delta=14$ pigments unique to the copepod samples, $\bullet=12$ pigments found in both types of samples. Pigment abbreviations: Allo $=$ alloxanthin $;$ cf Allo $=$ alloxanthin-like; Anthera $=$ antheraxanthin $;$ Asta $=$ astaxanthin, Beta $=\beta, \beta$ carotene, Beta-Eps $=\beta, \varepsilon$-carotene; B1, B2, B3 $=$ different forms of $\beta$ carotene; Cantha $=$ canthaxanthin, $\operatorname{chl} a=$ chlorophyll $a ; \operatorname{chl} b=$ chlorophyll $b$; chl $c=$ chlorophyll $c$; Croc $=$ crocoxanthin $; \mathrm{Di}=$ diesters of astaxanthin $;$ Diadino $=$ diadinoxanthin $;$ Diato $=$ diatoxanthin $;$ Echi $=$ echinenone; Fuco = fucoxanthin; Hexa $=19^{\prime}$-hexanoyloxy-fucoxanthin; Lut $=$ lutein $;$ Lyco $=$ lycopene; Mono $=$ monoesters of astaxanthin $;$ Peri $=$ peridinin $;$ Pheo $=$ pheophorbide $a ;$ Prasino $=$ prasinoxanthin $; \mathrm{P} 1$ and $\mathrm{P} 2=$ 2 unknown pigments in phytoplankton samples; Viola $=$ violaxanthin $_{i}$ Zea $=$ zeaxanthin; Z1-Z6 = 6 unknown pigments in copepod samples
NPSi1/NPSi2 were separated along the first ordination axis (Axis 1). This axis explained most of the variation $\mathrm{n}$ the data set; the eigenvalues of the first 4 axes were 70, 0.24, 0.02 and 0.01, respectively. The Sørensen similarity index showed that the carotenoids in the 2 NPSi treatments were most similar $(\mathrm{S}=90 \%)$, but the NSW and NP treatments were also rather similar $(\mathrm{S}=76 \%)$. Similarity was lower between the NSW and NP treatments on one side and the 2 NPSi treatments on the other ( $\mathrm{S}=42$ to $51 \%$ ). The copepod sample scores were separated from those of the phytoplankton along Axis 2 for the NSW and NP treatments and mainly along Axis 1 for the 2 NPSi treatments. The pigment scores of the same ordination (Fig. 2b) showed that chl $c$, fucoxanthin and diadinoxanthin were most associated with the phytoplankton samples of the NPSi treatments, whereas most other algal pigments were associated with the phytoplankton samples of the NSW and NP treatments. This indicates a larger pigment diversity in the NSW and NP treatments and dominance of diatoms in the NPSi treatments. Typical zooplankton pigments were found in the upperleft quadrant of the ordination, along with $\beta$-carotene and pheophorbide $a, 2$ pigments that occurred in both phytoplankton and copepod samples, but with higher relative abundances in the copepods.

The biomass in the phytoplankton samples, expressed as chl a concentration, was highest in the NPSi1 treatment $(59 \mathrm{nmol} \mathrm{chl} \mathrm{a}$ $\mathrm{l}^{-1}$ ) and lowest in the NSW treatment, which reflected the natural Baltic Sea conditions in

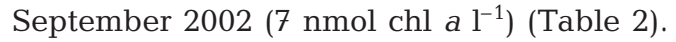
Significant $(p<0.05)$ negative linear regression coefficients between incubation time in $\mathrm{h}$ and pmol chl a $\mathrm{l}^{-1}$ were found for 3 of the 4 experiments (Ref: -47 ; NP: -340 ; NPSi2: -220) (Table 3). This may be considered a rough measure of grazing, but is in fact a complex combination of grazing and algal growth factors. The strongest decreasing

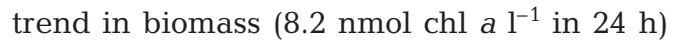
was observed in the NP treatment.

The major carotenoids in the phytoplankton of the NPSi treatments were fucoxanthin and diadinoxanthin, 66 to $71 \%$ and 11 to $17 \%$ of all carotenoids, respectively (Table 2). Together with high chl $c$ concentrations (Table 2), these carotenoids indicate that the biomass was completely dominated by diatoms in the NPSi treatments. This was 
also confirmed by microscopic observations of high abundances of diatoms belonging to the genera Chaetoceros, Cylindrotheca, Guinardia, Leptocylindrus and Skeletonema. Furthermore, the carotenoids alloxanthin, 19'-hexanoyloxy-fucoxanthin, peridinin and echinenone confirmed the microscopically observed occurrences of small-celled cryptophytes, prymnesiophytes, dinoflagellates and cyanobacteria

Table 2. Mean initial pigment concentrations $\left(\mathrm{nmol} \mathrm{l}^{-1}\right)$ in the phytoplankton samples $(\mathrm{n}=3, \mathrm{SD}=$ standard deviation) for each of the 4 treatments NSW, NP, NPSi1 and NPSi2. RCA = relative carotenoid abundance, $-=$ pigment not detected

\begin{tabular}{|c|c|c|c|c|c|c|c|c|c|c|c|c|}
\hline & \multicolumn{3}{|c|}{ NSW } & \multicolumn{3}{|c|}{ NP } & \multicolumn{3}{|c|}{ NPSi1 } & \multicolumn{3}{|c|}{ NPSi2 } \\
\hline & Mean & $\pm \mathrm{SD}$ & $(\mathrm{RCA} \%)$ & Mean & $\pm \mathrm{SD}$ & (RCA \%) & Mean & $\pm \mathrm{SD}$ & $(\mathrm{RCA} \%)$ & Mean & $\pm \mathrm{SD}$ & $(\mathrm{RCA} \%)$ \\
\hline Alloxanthin & 0.73 & \pm 0.02 & 11.1 & 0.87 & \pm 0.00 & 3.6 & 0.07 & \pm 0.02 & 0.1 & 1.09 & \pm 0.17 & 2.7 \\
\hline Antheraxanthin & - & & & 0.27 & \pm 0.01 & 1.1 & - & & & - & & \\
\hline$\beta, \beta$-carotene & 0.46 & \pm 0.03 & 7.0 & 2.29 & \pm 0.00 & 9.5 & 3.93 & \pm 0.20 & 5.3 & 2.23 & \pm 0.32 & 5.5 \\
\hline$\beta, \varepsilon$-carotene & 0.11 & \pm 0.01 & 1.7 & 0.24 & \pm 0.02 & 1.0 & - & & & 0.14 & \pm 0.03 & 0.3 \\
\hline Diadinoxanthin & 0.36 & \pm 0.02 & 5.5 & 1.56 & \pm 0.06 & 6.5 & 12.39 & \pm 0.18 & 16.6 & 4.30 & \pm 0.62 & 10.7 \\
\hline Diatoxanthin & 0.04 & \pm 0.01 & 0.6 & 0.12 & \pm 0.04 & 0.5 & 0.40 & \pm 0.01 & 0.5 & 0.13 & \pm 0.02 & 0.3 \\
\hline Echinenone & - & & & 0.23 & \pm 0.01 & 0.9 & 2.30 & \pm 0.21 & 3.1 & 0.21 & \pm 0.13 & 0.5 \\
\hline Fucoxanthin & 1.88 & \pm 0.02 & 28.5 & 5.09 & \pm 0.08 & 21.0 & 48.86 & \pm 2.07 & 65.6 & 28.55 & \pm 3.90 & 70.8 \\
\hline $\begin{array}{l}\text { 19'-hexanoyloxy- } \\
\text { fucoxanthin }\end{array}$ & 0.05 & \pm 0.02 & 0.8 & - & & & 0.86 & \pm 0.04 & 1.2 & 0.53 & \pm 0.06 & 1.3 \\
\hline Lutein & 0.63 & \pm 0.01 & 9.6 & 5.03 & \pm 0.21 & 20.8 & 0.84 & \pm 0.05 & 1.1 & 0.38 & \pm 0.07 & 0.9 \\
\hline Peridinin & 0.14 & \pm 0.02 & 2.1 & 1.12 & \pm 0.04 & 4.6 & 1.30 & \pm 0.05 & 1.7 & 0.74 & \pm 0.15 & 1.8 \\
\hline Prasinoxanthin & 0.12 & \pm 0.01 & 1.8 & - & & & - & & & - & & \\
\hline Violaxanthin & 0.34 & \pm 0.02 & 5.2 & 1.99 & \pm 0.05 & 8.2 & 0.84 & \pm 0.03 & 1.1 & 0.46 & \pm 0.06 & 1.2 \\
\hline Zeaxanthin & 0.88 & \pm 0.01 & 13.4 & 1.54 & \pm 0.15 & 6.4 & 1.18 & \pm 0.02 & 1.6 & 0.17 & \pm 0.03 & 0.4 \\
\hline Other carotenoids & 0.85 & \pm 0.11 & 12.9 & 3.86 & \pm 0.08 & 15.9 & 1.51 & \pm 0.28 & 2.0 & 1.40 & \pm 0.39 & 3.5 \\
\hline Chl a & 7.37 & \pm 0.05 & & 30.73 & \pm 0.65 & & 59.46 & \pm 1.82 & & 36.41 & \pm 5.33 & \\
\hline Chl $b$ & 1.56 & \pm 0.07 & & 5.65 & \pm 0.10 & & 0.80 & \pm 0.04 & & 1.04 & \pm 0.11 & \\
\hline $\mathrm{Chl} C$ & 1.70 & \pm 0.18 & & 7.10 & \pm 0.14 & & 62.31 & \pm 3.75 & & 44.30 & \pm 5.10 & \\
\hline Pheophorbide $a$ & 0.04 & \pm 0.02 & & - & & & 0.13 & \pm 0.00 & & - & & \\
\hline
\end{tabular}

Table 3. Significant $(\mathrm{p}<0.05)$ linear regressions with incubation time $(\mathrm{h})$ as predictor variable and pigment concentrations of the phytoplankton ( $\mathrm{pmol} \mathrm{l}^{-1}$ ) as response variables for each of the 4 treatments NSW, NP, NPSi1 and NPSi2 (n = 39 measurements), $\mathrm{rc}=$ regression coefficient, $\mathrm{ns}=$ not significant,$-=$ pigment not detected

\begin{tabular}{|c|c|c|c|c|c|c|c|c|}
\hline \multirow[b]{2}{*}{ Alloxanthin } & \multicolumn{2}{|c|}{$\begin{array}{c}\mathrm{NSW} \\
\mathrm{rc}\left(\mathrm{R}^{2}\right)\end{array}$} & \multicolumn{2}{|c|}{$\begin{array}{c}\mathrm{NP} \\
\mathrm{rc}\left(\mathrm{R}^{2}\right)\end{array}$} & \multicolumn{2}{|c|}{$\begin{array}{l}\text { NPSi1 } \\
\text { rc }\left(R^{2}\right)\end{array}$} & \multicolumn{2}{|c|}{$\begin{array}{l}\mathrm{NPSi} 2 \\
\mathrm{rc}\left(\mathrm{R}^{2}\right)\end{array}$} \\
\hline & -5.7 & $(0.71)$ & -8.1 & $(0.58)$ & ns & & -14.8 & $(0.36)$ \\
\hline Antheraxanthin & - & & -2.9 & $(0.23)$ & - & & - & \\
\hline$\beta, \beta$-carotene & ns & & -18.0 & $(0.39)$ & $\mathrm{ns}$ & & ns & \\
\hline$\beta, \varepsilon$-carotene & ns & & ns & & - & & ns & \\
\hline Diadinoxanthin & -5.3 & $(0.74)$ & -31.9 & $(0.87)$ & -100.1 & $(0.27)$ & ns & \\
\hline Diatoxanthin & -0.6 & $(0.25)$ & -3.6 & $(0.55)$ & +3.7 & $(0.13)$ & -4.8 & $(0.49)$ \\
\hline Echinenone & - & & +1.8 & $(0.13)$ & ns & & ns & \\
\hline Fucoxanthin & -6.0 & $(0.13)$ & -75.5 & $(0.75)$ & ns & & ns & \\
\hline 19'-Hexanoyloxy-fucoxanthin & ns & & - & & -19.6 & $(0.43)$ & -7.6 & $(0.18)$ \\
\hline Lutein & -5.5 & $(0.61)$ & -40.5 & $(0.58)$ & -6.1 & $(0.11)$ & -3.8 & $(0.29)$ \\
\hline Peridinin & -1.0 & $(0.20)$ & -26.7 & $(0.88)$ & ns & & ns & \\
\hline Prasinoxanthin & -1.8 & $(0.45)$ & - & & - & & - & \\
\hline Violaxanthin & -3.2 & $(0.52)$ & -17.0 & $(0.59)$ & +7.2 & $(0.25)$ & -2.0 & $(0.15)$ \\
\hline Zeaxanthin & -11.9 & $(0.75)$ & -13.4 & $(0.53)$ & ns & & ns & \\
\hline Chl a & -47.3 & $(0.46)$ & -339.5 & $(0.63)$ & ns & & -219.6 & $(0.18)$ \\
\hline Chl $b$ & -14.7 & $(0.42)$ & -54.1 & $(0.53)$ & ns & & -11.4 & $(0.43)$ \\
\hline $\mathrm{Chl} C$ & -11.5 & $(0.27)$ & -125.0 & $(0.71)$ & ns & & ns & \\
\hline Pheophorbide $a$ & +1.5 & $(0.26)$ & - & & +3.7 & $(0.40)$ & - & \\
\hline
\end{tabular}


(Merismopedia, Microcystis, Anabaena), respectively. The phytoplankton pigment composition of the NSW and NP treatments, together with microscopic observations, revealed a mixture of chlorophytes ( $\mathrm{chl} b$, lutein, violaxanthin, antheraxanthin, zeaxanthin), particularly Planktonema (Ulotrichales) and Scenedesmus and other Chlorococcales, diatoms represented mainly by Skeletonema (fucoxanthin, diadinoxanthin), dinoflagellates (peridinin), cryptophytes (alloxanthin) and cyanobacteria (zeaxanthin, echinenone). Major differences between the 4 treatments were the much lower relative abundances and visibly thinner silica shells of the diatoms, and the much higher relative abundances of chlorophytes in the NSW and NP treatments compared with the 2 NPSi treatments.

Trends indicative of selective grazing during the experiments were shown by linear regression analysis of the pigments in the phytoplankton communities with time as predictor variable (Table 3 ). However, it should be kept in mind that these trends only represent a rough measure of grazing, because they summarise a complex combination of grazing and algal growth factors. In the NSW and NP treatments the copepods exploited a more diverse diet (negative regression coefficients for 12 and 13 pigments, respectively) than in the NPSi1 and NPSi2 treatments (negative regression coefficients for 3 and 7 pigments, respectively). The largest negative regression coefficients for carotenoids were found for fucoxanthin, diadinoxanthin, lutein and peridinin in the NP treatment and for diadinoxanthin and 19'-hexanoyloxy-fucoxanthin in the NPSi1 treatment (Table 3). These results suggest significant selective grazing on diatoms, chlorophytes and dinoflagellates in the NP treatment, and on prymnesiophytes in the NPSi1 treatment, while grazing rates were very low in the other 2 treatments as well as on other algal groups in the NP and NPSi1 treatments. Of the carotenoids reported to be precursors of astaxanthin, lutein had significant negative regression coefficients in all treatments, albeit 7 to $11 \times$ lower in the 3 other treatments than in the NP treatment. This observation underlines the importance of chlorophytes as prey for copepods. Significant regression coefficients for zeaxanthin were found in the NP and NSW treatments, but for $\beta, \beta$-carotene only in the NP treatment. Five positive regression coefficients were also found (Table 3); these may be indicative of growth of a specific algal group, carotenoid dynamics such as xanthophyll cycling or copepod faecal pellets (pheophorbide a). However, all 5 positive regression coefficients were very small and therefore of no or negligible importance in the present study.

The zooplankton density (ind. $\mathrm{l}^{-1}$; mean $\pm \mathrm{SD}$ ) in the 4 experiments was $49 \pm 3$ copepods and no other zooplankton in the NSW treatment, $41 \pm 17$ copepods and
$3 \pm 1$ other zooplankton in the NP treatment, $41 \pm 8$ copepods and no other zooplankton in the NPSi1 treatment, $68 \pm 6$ copepods and $3 \pm 1$ other zooplankton in the NPSi2 treatment. Other zooplankton organisms were all more than $10 \times$ smaller in body size than the copepods and were ignored in the calculations. The dominant calanoid copepod genus in all experiments was Acartia, with relative abundances of $89 \%$ (NSW), $99 \%$ (NP), $98 \%$ (NPSi1) and 95\% (NPSi2) of all copepods. The main accompanying copepod genus was Temora, but single Eurytemora, Paracalanus and Pseudocalanus species were observed as well.

In July, the initial pigment content per copepod individual of the wild copepods (Fig. 3, NP and NPSi1, $t=0 \mathrm{~h}$ ) was generally higher than in September (Fig. 3, NSW and NPSi2, $t=0 \mathrm{~h}$ ). The major carotenoids in the copepod samples of the NPSi treatments consisted of $\sim 8 \%$ of algal carotenoids that are involved in the biosynthesis of astaxanthin ( $\beta$-carotene, zeaxanthin/lutein), $\sim 68 \%$ of other algal carotenoids (fucoxanthin, diadinoxanthin, 19'hexanoyloxy-fucoxanthin) and $24 \%$ of zooplankton carotenoids (free astaxanthin, monoesters of astaxanthin, diesters of astaxanthin, alloxanthin-like). The major carotenoids in the copepods of the NSW and NP treatments consisted of $\sim 17 \%$ of algal carotenoids that are involved in the biosynthesis of astaxanthin ( $\beta$-carotene, zeaxanthin/lutein), $\sim 26 \%$ of other algal carotenoids (fucoxanthin, diadinoxanthin, peridinin, violaxanthin) and $\sim 57 \%$ of zooplankton carotenoids (free astaxanthin, mono- and diesters of astaxanthin, alloxanthin-like). $\beta$-carotene and zeaxanthin/lutein, as well as the typical zooplankton carotenoids free astaxanthin, monoesters of astaxanthin and alloxanthinlike, showed maxima in the early morning hours (before or just after sunrise) in the NP and NPSi1 treatments (Fig. 3). In the NSW and NPSi2 treatments maxima were less pronounced or absent. Zeaxanthin/lutein, astaxanthin and alloxanthin-like were highest in the copepods in the NP treatment, while $\beta$-carotene and monoesters of astaxanthin were in the same order of magnitude in the NP and NPSi1 treatments. The higher abundance of algal pigments in the 2 NPSi treatments depended on the higher abundance of larger diatom cells in colonies that became captured on the $200 \mu \mathrm{m}$ mesh size plankton net together with the copepods while sampling.

In the NSW treatment, algal groups with diadinoxanthin (positive $\mathrm{TR}_{\text {net }}$ ) and no or little fucoxanthin (negative $\mathrm{TR}_{\mathrm{net}}$ ) were preferred as prey by the copepods (Fig. 4a). A more varied diet was observed in the NP treatment, with positive $\mathrm{TR}_{\text {net }}$ values for peridinin, violaxanthin, fucoxanthin and diadinoxanthin throughout most of the experiment (Fig. 4c). In both NPSi treatments the copepods showed the strongest 
(a) $\beta$-Carotene

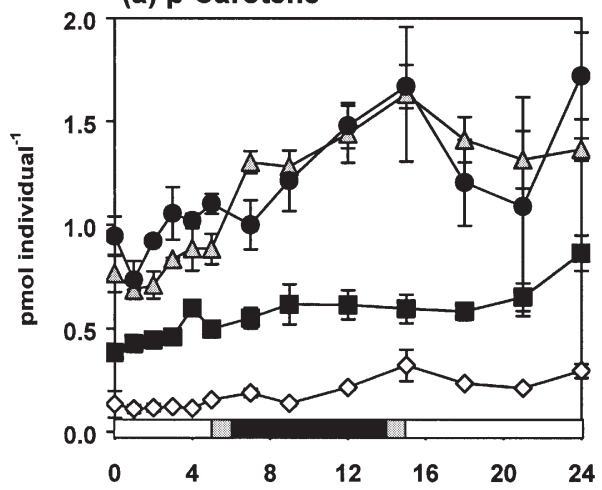

(c) Astaxanthin

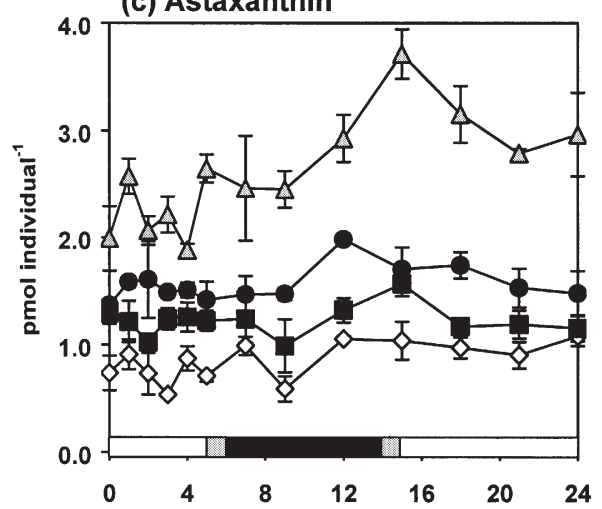

(e) Alloxanthin-like

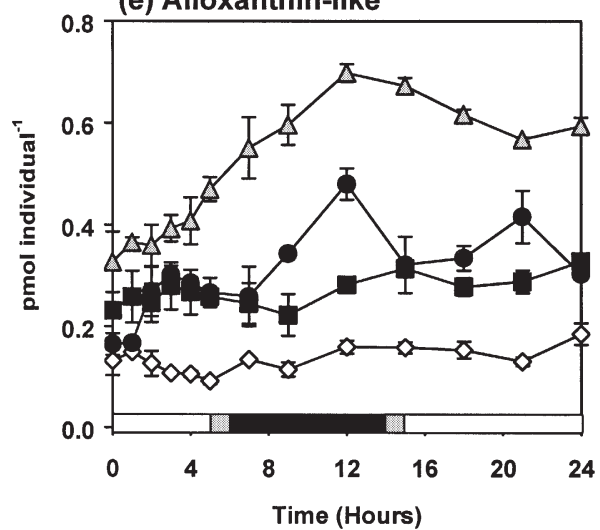

(b) Zeaxanthin / lutein

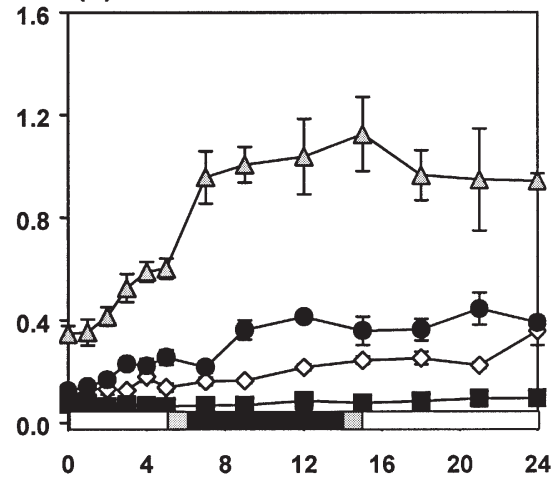

(d) Monoesters of astaxanthin

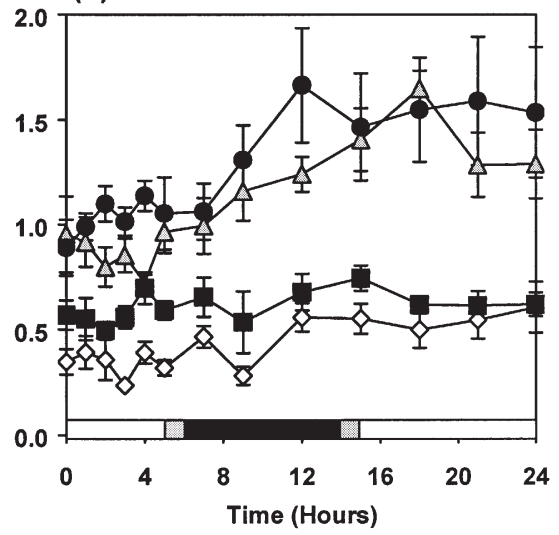

Fig. 3. Content of carotenoids in the calanoid copepods during the 4 treatments NSW, NP, NPSi1 and NPSi2, expressed as pmol per copepod individual. (a) Total $\beta$-carotene, (b) zeaxanthin/lutein, (c) astaxanthin, (d) monoesters of astaxanthin, (e) alloxanthinlike. Note the different scales on the $y$-axes. The $x$-axis shows the light period (white + grey bars) and the dark period (black bar) during the NP and NPSi treatments in July, and the light period (white bar) and dark period (black + grey bars) during the NSW and NPSi2 treatments in September. Error bars show mean $\pm 1 \mathrm{SE}$

preference for 19'-hexanoyloxy-fucoxanthin containing algae (prymnesiophytes) (Fig. 4e,g). Violaxanthin, fucoxanthin and diadinoxanthin had also positive $\mathrm{TR}_{\text {net }}$ values (around 0.2) in the NPSi1 treatment, as well as violaxanthin (up to ca. 0.5) in the NPSi2 treatment. In the NPSi2 treatment, selection was against algae containing peridinin (dinoflagellates).
Carotenoids reported to be involved in the biosynthesis of astaxanthin, total $\beta$-carotene $(\beta, \beta$-carotene, $\beta, \varepsilon$-carotene and their cis-forms) and zeaxanthin/lutein (the HPLC column used for the copepods samples could not separate these 2 carotenoids) were abundant in both phytoplankton and copepod samples. The $\mathrm{TR}_{\text {net }}$ was calculated for total $\beta$-carotene and for zeaxan- 

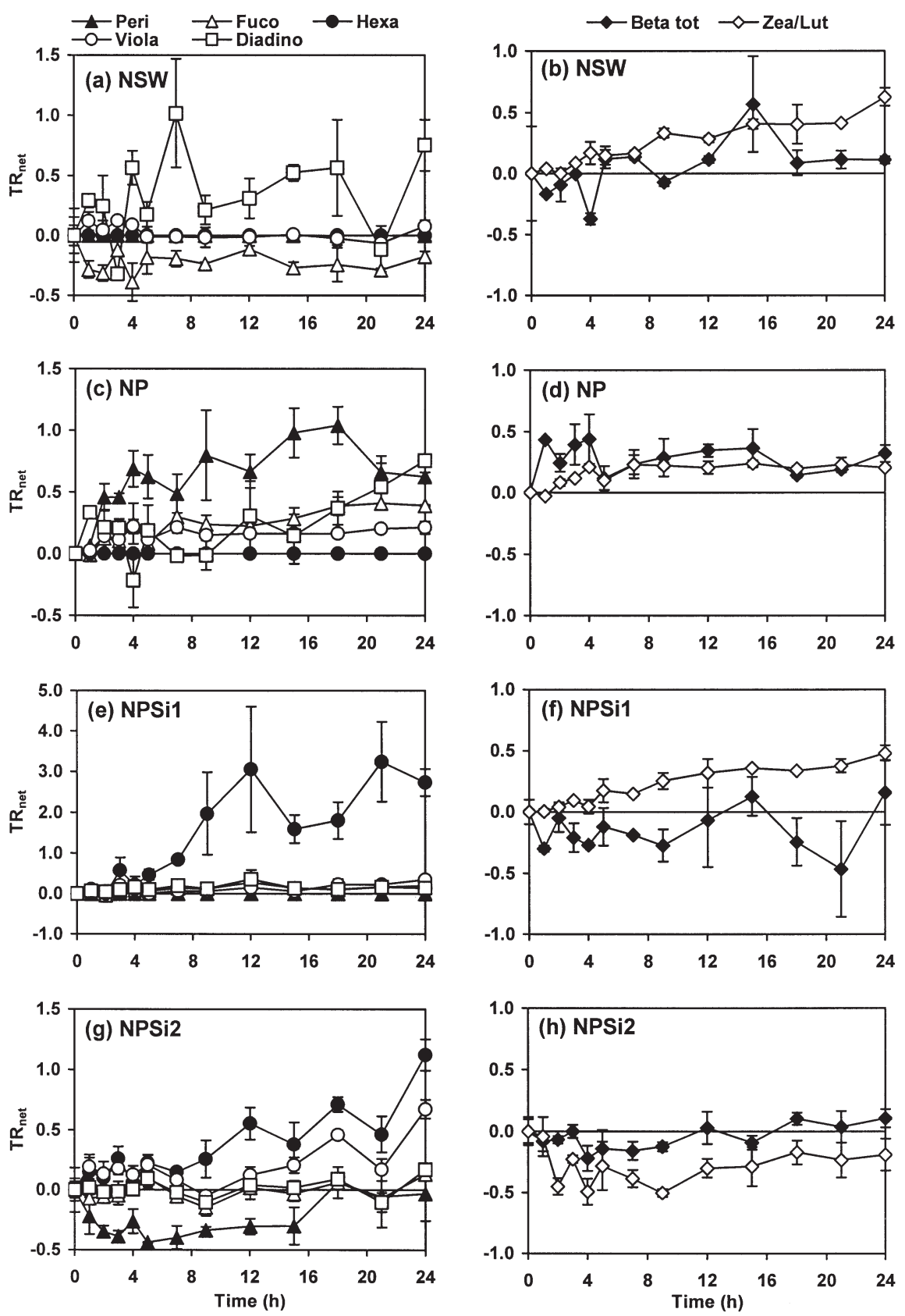

Fig. 4. Change in transfer ratios (TR $\left.\mathrm{TR}_{\text {net }}\right)$ throughout the experiments for the 4 treatments NSW, NP, NPSi1 and NPSi2 for the carotenoids total $\beta$-carotene (Beta), diadinoxanthin (Diadino), fucoxanthin (Fuco), 19'-hexanoyloxy-fucoxanthin (Hexa), peridinin (Peri), violaxanthin (Viola) and zeaxanthin/lutein (Zea/Lut). Note the different scales on the $y$-axes. Error bars show mean $\pm 1 \mathrm{SE}$

thin/lutein. In the NP treatment $\mathrm{TR}_{\text {net }}$ values for total $\beta$-carotene were high throughout the experiment (Fig. 4d), suggesting accumulation of total $\beta$-carotene in the copepods. The $\mathrm{TR}_{\text {net }}$ values for total $\beta$-carotene were generally lower in the NSW treatment than in the NP treatment and lowest in the NPSi treatments (Fig. 4b,f,h), but maxima occurred at $t=15 \mathrm{~h}$ in the
NSW and NPSi1 treatments. The TR ${ }_{\text {net }}$ value for zeaxanthin/lutein increased steadily in the NSW, NP and NPSi1 treatments, but was negative throughout the NPSi2 treatment. The increases in zeaxanthin/ lutein may have resulted from biosynthesis (from $\beta$-carotene), but also from selective grazing on chlorophytes. 


\section{DISCUSSION}

In our experiments the calanoid copepods fed selectively on the phytoplankton in the different nutrient treatments. One obvious trend was that they did not graze on diatoms in the 2 NPSi treatments where diatoms dominated, while diatoms were among the major food items in the NP treatment. Some authors, e.g. Kleppel et al. (1991), have previously reported copepod grazing selectivity against diatoms, while others found that copepods feed selectively on diatoms (Meyer-Harms et al. 1999, Gasparini et al. 2000). It has also been found that copepods sometimes do not feed selectively at all (Kleppel 1998). Based on studies of growth, fecundity and egg mortality of copepods, it may be true that only fast-growing and nutrientreplete diatom cells are high-quality food for copepods, while senescent cells and cells with a high C:N ratio have a poor food quality (Kiørboe 1989, Jónasdóttir 1994). In a previous, similar mesocosm experiment carried out on the Norwegian Atlantic coast, we showed that the phytoplankton in the NPSi treatment (completely dominated by diatoms) suffered from Nlimitation (Van Nieuwerburgh et al. unpubl.), which may have affected food preference dynamics. Both in the earlier and the present studies, the reason for the copepods avoiding consumption of diatoms in the NPSi treatments may also have been that the diatoms in these treatments were exceptionally heavily silicified, and therefore difficult to eat.

In the present study, we tested how the production of the important antioxidant astaxanthin in calanoid copepods is affected when they graze on different phytoplankton communities. It is generally recognised that the main precursor of astaxanthin in zooplankton is $\beta, \beta$-carotene (Katayama et al. 1973, Bandaranayake \& Gentien 1982). It has also been demonstrated that zeaxanthin is metabolised into astaxanthin via $\beta$ doradexanthin, while alloxanthin and diatoxanthin can be transformed into didehydroastaxanthin and tetradehydroastaxanthin, respectively (Ohkubo et al. 1999). Lutein, a carotenoid frequently reported as common in crustaceans, is converted into $\alpha$-doradexanthin, but there is no conclusive evidence concerning a further conversion into its isomer, $\beta$-doradexanthin, leading to the formation of astaxanthin (Ohkubo et al. 1999). However, astaxanthin biosynthesis from lutein has been suggested to occur in the ovaries of the crayfish Cherax quadricarinatus (Sagi et al. 1995), as well as in developing eggs of the crayfish Astacus leptodactylus (Berticat et al. 2000). This would imply that lutein might also act as a precursor of astaxanthin in crustaceans.

Our results suggest that the quality of the phytoplankton community as food for calanoid copepods depends both on the quantity and the quality of the food items (biomass and community composition). Despite a similar phytoplankton pigment composition in the NSW and NP treatments (as we showed by PCA; Fig. 2), the NP treatment yielded a much higher astaxanthin production in the copepods in our experiments (Fig. 3). This could be attributed to the $\sim 5 \times$ higher phytoplankton biomass in the NP treatment; the relative abundance of $\beta$-carotene is similar (NSW: $7.0 \%, \mathrm{NP}: 9.5 \%$ ) in the 2 treatments, but the total $\beta$-carotene available to the copepods was $5 \times$ higher in the NP treatment (Table 2). Moreover, other presumed precursors of astaxanthin, lutein and zeaxanthin available to the copepods were 8 and $2 \times$ higher in the NP treatment, respectively. Thus, a higher availability of chlorophytes in the NP treatment, next to diatoms and dinoflagellates, may have been advantageous for the production of astaxanthin in addition to the higher biomass. Both NPSi treatments had higher biomass than the NP treatment (Table 2), but lower astaxanthin production (Fig. 3), which suggests that the quality of the available prey is more important for astaxanthin production than biomass per se. Astaxanthin production was higher in the NPSi1 treatment than in the NPSi2 treatment (Fig. 3), especially the production of astaxanthin monoesters. The pigment composition of the phytoplankton in the $2 \mathrm{NPSi}$ treatments was very similar (as we showed by PCA; Fig. 2), but there were some other differences which may have affected both grazing and astaxanthin production: (1) the NPSi1 treatment had a factor 1.5 higher biomass based on chls $a+c$ (Table 2), and thus a relatively higher access to $\beta$-carotene, lutein and zeaxanthin, (2) higher consumption of prymnesiophytes in NPSi1 treatment (Table 3), (3) seasonal differences in life cycle and/or physiology of the copepod community between July (NPSi1) and September (NPSi2), and (4) the difference in copepod density between NPSi1 and NPSi2 (41 and 68 ind. $\mathrm{l}^{-1}$, respectively). The transfer ratios of $\beta$-carotene were similar for the 2 treatments, but that of zeaxanthin/lutein was positive for the NPSi1 treatment and negative for the NPSi2 treatment. This suggests that the difference in astaxanthin production is mainly related to the transfer of astaxanthin precursors.

Since planktonic crustaceans cannot synthesise carotenoid pigments de novo Matsuno (1989), and because zooplankton body pigments are not normally present in phytoplankton algae, our observed variations in astaxanthin and alloxanthin-like carotenoid content in the copepods provide indications of diurnal variation in body pigment metabolism. In our experiments, the concentrations of copepod body carotenoids peaked around sunrise (Fig. 3). The most 
pronounced peak in astaxanthin content per copepod individual occurred in the NP treatment, with levels about twice the initial value. The occurrence of these peaks is probably driven by increased feeding activity during the night because also $\beta$-carotene and zeaxanthin/lutein showed the same trends. A diurnal feeding pattern in zooplankton was described by Kleppel et al. (1985) from Los Angeles Harbor, California, with peaks for both feeding activity and total carotenoid content during the night. The relationship between total carotenoid content and feeding activity could be described by a linear regression model. Also Stearns (1986) revealed a nocturnal feeding pattern in Acartia tonsa Dana and a negative correlation between feeding and light intensity during daylight hours in a North Carolina estuary. Based on these results and laboratory experiments, Stearns (1986) hypothesised that feeding might be a behaviour controlled by light separate from copepod migration. A photoprotective role of astaxanthin in copepods was suggested by Hairston $(1979 a, b)$, and the rationale for the periodicity we discovered in our study may be that astaxanthin is accumulated by the zooplankton during the night and utilised for photoprotection and other antioxidant activities during the day.

Our experiments were short-term and were carried out in the laboratory. Therefore the results cannot directly be translated to nature, despite the use of natural communities of phytoplankton and copepods. However, some of the results we obtained may play a part in complex, naturally occurring processes. In this study, we showed that phytoplankton community composition and biomass have profound effects on the production of the vital compound astaxanthin in calanoid copepods. Zooplankton occupies a key position in the pelagic food web as it transfers the organic energy produced by unicellular algae through photosynthesis to higher trophic levels such as pelagic fish stocks. The important role of calanoid copepods in food webs worldwide (Mauchline 1998) implies that the whole food web may be affected by the quality and quantity of the phytoplankton as prey for higher trophic levels. With a more varied diet and high biomass (NP treatment) astaxanthin production in the copepods was highest. Astaxanthin production was much lower with high phytoplankton biomass dominated by large heavily silicified diatoms (NPSi treatment). These results suggest a positive effect of eutrophication, but not when excess $\mathrm{Si}$ is available for phytoplankton growth. Large-scale and long-term eutrophication of the Baltic Sea may lead to lower phytoplankton diversity, with blooms of 1 or a few species, and thus a less varied diet for zooplankton, which in the light of our experiments may lead to a lower production of astaxanthin in the food web.
Acknowledgements. This study was financed by the Knut and Alice Wallenberg Foundation (Sweden) and the Norsk Hydro Research Foundation (Norway). We are grateful to Rostock University (Germany) for providing research facilities at the Zingst field station in June 2001 and to Thalassa AB for the gift of Haematococcus pluvialis cysts. We thank M. McCausland, M. P. Barros, J. Johansson and D. Larson (Uppsala University) for assistance and good company during the mesocosm experiment, and H. Baudler, H. Schubert, P. Feuerpfeil and V. Reif (Rostock University) for help in various ways. We are grateful to 4 anonymous reviewers for helping us to improve this paper.

\section{LITERATURE CITED}

Amcoff P, Börjeson H, Lindeberg J, Norrgren L (1998) Thiamine (vitamin $\mathrm{B}_{1}$ ) concentrations in feral Baltic salmon exhibiting the M74 syndrome. Am Fish Soc Symp 21: 82-89

Ban S, Burns C, Castel J, Chaudrun Y and 19 others (1997) The paradox of diatom-copepod interactions. Mar Ecol Prog Ser 157:287-293

Bandaranayake WM, Gentien P (1982) Carotenoids of Temora turbinata, Centropages furcatus, Undinula vulgaris and Euchaeta russelli. Comp Biochem Physiol Part B 72:409-414

Barros MP, Pedersén M, Colepicolo P, Snoeijs P (2003) Selfshading protects phytoplankton communities against $\mathrm{H}_{2} \mathrm{O}_{2}$-induced oxidative damage. Aquat Microb Ecol 30: $275-282$

Bengtsson BE, Hill C, Bergman Å, Brandt I, Johansson N, Magnhagen C, Södergren A, Thulin J (1999) Reproductive disturbance in Baltic fish: a synopsis of the FiRE project. Ambio 28:2-8

Berticat $O$, Nègre-Sadargues G, Castillo R (2000) The metabolism of astaxanthin during embryonic development of the crayfish Astacus leptodactylus Eschscholtz (Crustacea, Astacidea). Comp Biochem Physiol Part B 127:309-318

Buffan-Dubau E, Carman KR (2000) Diel feeding behaviour of meiofauna and their relationships with microalgal resources. Limnol Oceanogr 45:381-395

Edge R, McGarvey DJ, Truscott TG (1997) The carotenoids as antioxidants - a review. Photochem Photobiol B 41: $189-200$

Elmgren R (1989) Man's impact on the ecosystem of the Baltic Sea: energy flows today and at the turn of the century. Ambio 18:326-332

Gasparini S, Dara MH, Antajan E, Tackx M, Rousseau V, Parent JY, Lancelot C (2000) Mesozooplankton grazing during the Phaeocystis globosa bloom in the southern bight of the North Sea. J Sea Res 43:345-356

Guillard RRL, Ryther JH (1962) Studies of marine plankton diatoms I. Cyclotella nana Hustedt and Detonula confervacea (Cleve) Gran. Can J Microbiol 8:229-239

Hairston NG (1979a) The effect of temperature on carotenoid photoprotection in the copepod Diaptomus nevadensis. Comp Biochem Physiol Part A 62:445-448

Hairston NG (1979b) The adaptive significance of color polymorphism in two species of Diaptomus (Copepoda). Limnol Oceanogr 24:15-37

Irigoien X, Harris RP, Verheye HM, Joly P and 14 others (2002) Copepod hatching success in marine ecosystems with high diatom concentrations. Nature 419:387-389

Jacobsen A, Egge JK, Heimdal BR (1995) Effects of increased concentration of nitrate and phosphate during a spring bloom experiment in mesocosm. J Exp Mar Biol Ecol 187: $239-251$ 
Jansson BO, Dahlberg K (1999) The environmental status of the Baltic Sea in the 1940s, today and in the future. Ambio 28:312-319

Jeffrey SW, Vesk M (1997) Introduction to marine phytoplankton and their pigment signatures. In: Jeffrey SW, Mantoura RFC, Wright SW (eds) Phytoplankton pigments in oceanography: guidelines to modern methods. UNESCO, Paris, p 37-84

Jónasdóttir SH (1994) Effects of food quality on the reproductive success of Acartia tonsa and Acartia hudsonica: laboratory observations. Mar Biol 121:67-81

Jónasdóttir SH, Kiørboe T, Tang KW, St John M, Visser A, Saiz E, Dam HG (1998) Role of diatoms in copepods production: good, harmless or toxic? Mar Ecol Prog Ser 172: 305-308

Katayama T, Kunisaki Y, Shimaya M, Simpson KL, Chichester CO (1973) The biosynthesis of astaxanthin. XIV. The conversion of labelled $\beta$-carotene-15, $15^{\prime}-{ }^{3} \mathrm{H}_{2}$ into astaxanthin in the crab, Portunus trituberculatus. Comp Biochem Physiol Part B 46:269-272

Kiørboe T (1989) Phytoplankton growth rate and nitrogen content implications for feeding and fecundity in a herbivorous copepod. Mar Ecol Prog Ser 55:229-234

Kleppel GS (1993) On the diets of calanoid copepods. Mar Ecol Prog Ser 99:183-195

Kleppel GS (1998) Plant and animal pigments as trophodynamic indicators. In: Soule DF, Kleppel GS (eds) Marine organisms as indicators. Springer-Verlag, New York, p 73-90

Kleppel GS, Willbanks L, Pieper RE (1985) Diel variation in body carotenoid content and feeding activity in marine zooplankton assemblages. J Plankton Res 4:569-580

Kleppel GS, Holliday DV, Pieper RE (1991) Trophic interactions between copepods and microplankton: a question about the role of diatoms. Limnol Oceanogr 36:172-178

Koski M, Klein Breteler W, Schogt N (1998) Effect of food quality on rate of growth and development of the pelagic copepod Pseudocalanus elongatus (Copepoda, Calanoida). Mar Ecol Prog Ser 170:169-187

Legendre L (1990) The significance of microalgal blooms for fisheries and for the export of particulate organic carbon in oceans. J Plankton Res 12:681-699

Leppäkoski E, Mihnea PA (1996) Enclosed seas under maninduced change: a comparison between the Baltic and Black Seas. Ambio 25:380-389

Lundström J, Börjeson H, Norrgren L (1998) Clinical and pathological studies of Baltic salmon suffering from yolk sac fry mortality. Am Fish Soc Symp 21:26-72

Matsuno T (1989) Animal carotenoid. In: Krinsky NI, Mathews-Roth MM, Taylor F (eds) Carotenoids chemistry and biology. Plenum Press, New York, p 59-74

Mauchline J (1998) The biology of calanoid copepods. Academic Press, San Diego

Editorial responsibility: Otto Kinne (Editor),

Oldendorf/Luhe, Germany
Meyer-Harms B, Irigoien X, Head R, Harris R (1999) Selective feeding on natural phytoplankton by Calanus finmarchicus before, during and after the 1997 spring bloom in the Norwegian Sea. Limnol Oceanogr 44:154-165

Miralto A, Barone G, Romano G, Poulet SA and 7 others (1999) The insidious effect of diatoms on copepod reproduction. Nature 402:173-176

Mueller-Dombois D, Ellenberg H (1974) Aims and methods of vegetation ecology. John Wiley \& Sons, New York

Ohkubo M, Tsushima M, Maoka T, Matsuno T (1999) Carotenoids and their metabolism in the goldfish Carassius auratus (Hibuna). Comp Biochem Physiol Part B 124: 333-340

Paffenhöfer GA (2002) An assessment of the effects of diatoms on planktonic copepods. Mar Ecol Prog Ser 227:305-310

Pettersson A, Lignell P (1999) Astaxanthin deficiency in eggs and fry of Baltic salmon (Salmo salar) with the M74 syndrome. Ambio 28:43-47

Pickova J, Kiessling A, Pettersson A, Dutta P (1999) Fatty acid and carotenoid composition of eggs from two nonanadromous Atlantic salmon stocks of cultured and wild origin. Fish Physiol Biochem 21:147-156

Runge JA (1988) Should we except a relationship between primary production and fisheries? The role of copepod dynamics as a filter of trophic variability. Hydrobiologia 167/168:61-71

Sagi A, Rise M, Isam K, Arad S (1995) Carotenoids and their derivatives in organs of the maturing female crayfish Cherax quadricarinatus. Comp Biochem Physiol Part B 112:309-313

Snoeijs P (1999) Diatoms and environmental change in brackish waters. In: Stoermer EF, Smol JP (eds) The diatoms: applications to the environmental and earth sciences. Cambridge University Press, Cambridge, p 298-333

Sommer U (1994) Are marine diatoms favoured by high Si:N ratios? Mar Ecol Prog Ser 115:300-315

Stearns DE (1986) Copepod grazing behavior in simulated natural light and its relation to nocturnal feeding. Mar Ecol Prog Ser 30:65-76

ter Braak CJ, Šmilauer P (1998) CANOCO reference manual and user's guide to Canoco for Windows: software for canonical community ordination (version 4). Microcomputer Power, Ithaca, NY

Wright SW, Jeffrey SW (1997) High-resolution HPLC system for chlorophylls and carotenoids of marine phytoplankton. In: Jeffrey SW, Mantoura RFC, Wright SW (eds) Phytoplankton pigments in oceanography: guidelines to modern methods. UNESCO, Paris, p 327-341

Wright SW, Jeffrey SW, Mantoura RFC (1997) Evaluation of methods and solvents for pigment extraction. In: Jeffrey SW, Mantoura RFC, Wright SW (eds) Phytoplankton pigments in oceanography: guidelines to modern methods. UNESCO, Paris, p 261-282

Submitted: October 16, 2002; Accepted: February 28, 2003 Proofs received from author(s): May 8, 2003 